\title{
Ice-Crystal Icing Accretion Studies at the NASA Propulsion Systems Laboratory
}

\author{
Peter Struk, Juan Agui, Michael King, and Thomas Ratvasky \\ NASA John Glenn Research Center
}

Tadas Bartkus and Jen-Ching Tsao

Ohio Aerospace Institute

\begin{abstract}
This paper describes an ice-crystal icing experiment conducted at the NASA Propulsion System Laboratory during June 2018. This test produced ice shape data on an airfoil for different test conditions similar to those inside the compressor region of a turbo-fan jet engine. Mixed-phase icing conditions were generated by partially freezing out a water spray using the relative humidity of flow as the primary parameter to control freeze-out. The paper presents the ice shape data and associated conditions which include pressure, velocity, temperature, humidity, total water content, melt ratio, and particle size distribution. The test featured a new instrument traversing system which allowed surveys of the flow and cloud. The purpose of this work was to provide experimental ice shape data and associated conditions to help develop and validate ice-crystal icing accretion models. The results support previous experimental observations of a minimum melt-ratio threshold for accretion to occur as well as the existence of a plateau region where the icing severity is high for a range of melt ratios. However, a maximum limit for melt ratio, which is suggested in the ice crystal icing literature, was not observed perhaps complicated by the potential for some supercooling of the water at these conditions.
\end{abstract}

\section{Introduction}

Some jet-engine power-loss events are attributed to icing that occurs due to the ingestion of ice-crystals at high altitudes [1]. NASA is investigating the fundamental physical mechanisms of such icing which occurs in core compressor regions of jet engines [2]. The primary goal of these investigations is to improve understanding of the ice growth physics and expand engine aero-thermodynamic modeling capability to predictively assess the onset and growth of ice in current and future engines during flight [3-6].

The NASA Propulsions Systems Laboratory (PSL) has recently added a capability to inject ice particles into an operating jet-engine [7]. To date, a number of successful test programs using both jet engines and test rigs have been performed at the facility offering insight into the engine ice-crystal icing [8-10]. At PSL, the ice particles are generated using liquid-water spray nozzles which are injected upstream of the test section in a plenum area. The water droplets freeze prior to reaching the test section due to a combination of convective and evaporative cooling. Once inside the jet-engine, the ice particles are presumed to break-apart and begin to melt generating a mixed-phase condition before reaching the accretion site in the compressor.

Due to spatial and access constraints with respect to instrumentation, it is difficult to study the physics of such accretions directly inside the engine. Thus, NASA is simulating the internal engine conditions Page 1 of 11 leading to icing but in an external flow environment. The desired conditions to be controlled include (1) wet-bulb temperature, (2) particle size distribution, and (3) melted portion of incoming ice. However, it has been difficult to vary these parameters independently. As will be discussed, the relative humidity in the plenum was the main parameter varied which affected multiple icing parameters in the test section. The key icing parameters being measured at the test section include the total water content, melt ratio, particle size distribution, and aero-thermal conditions such as pressure, velocity, temperature, and humidity.

This paper describes an experiment on ice-crystal icing using PSL that took place in June 2018. The primary objective of this test was to generate a set of ice shapes on an airfoil model under wellcharacterized conditions to help develop and validate ice-crystal accretion models. A NACA 0012 airfoil was used for this testing as it is well characterized for ice accretion from extensive testing in supercooled liquid water (e.g. $[11,12])$ thereby eliminating the need to characterize certain aspects of the airfoil. The ice shapes were generated across a series of four different flow conditions where the relative humidity in the plenum was the primary parameter varied. In addition, tests were conducted at an angle of attack (AOA) of $0^{\circ}$ and $-4^{\circ}$. This paper presents four ice accretions at different melt ratios for one flow condition at $0^{\circ}$ AOA. The accretions at other flow conditions and AOAs are planned to be reported at a later date. However, some results from those conditions can be found in complementary papers presented in this conference which provide more details of instrumentation [13] or use the data for model comparison [14].

The June 2018 testing built upon results from a similar testing at the PSL in 2016 [15]. Analysis of the 2016 test results showed that there were radial variations in flow and cloud properties due to the spray bar patterns selected. Since not all measurements were made at centerline in 2016, some key flow and cloud properties needed to be extrapolated from the available data to estimate conditions at the ice accretion site. For the 2018 PSL testing, an instrument traversing system was developed which allowed direct measurements of centerline conditions at the accretion sites as well as allowing the ability to perform flow surveys at various positions within the cloud. Finally, there were multiple additional objectives of the June 2018 PSL which are not described in this paper.

\section{Experimental Description}

This section highlights changes in the 2018 experimental setup from those in 2016. The 2018 experiment includes a new instrument traversing system. 


\section{Airfoil Model}

The NACA 0012 airfoil model has a $266.7 \mathrm{~mm}$ (10.5 inch) chord length and has been previous described [15]. The 2016 testing included surface polyimide heaters on the solid aluminum extension to prevent ice from forming on the extensions. For the 2018 tests, the heaters were removed due to the tendency for the heaters to cause undesired asymmetric ice shedding. Furthermore, the aluminum extensions were black anodized for the 2018 tests to allow for good imaging contrast for ice that forms on the extensions.

\section{Traversing System}

An instrument and test article traversing system was developed for this test. The system included four separate traversing mechanisms specifically for: (1) intrusive probes, (2) non-intrusive probes, (3) airfoil / test article, and an (4) isokinetic, or canister-type, probes. The overall installation integrated inside the PSL facility is shown in Figures 1 and 2.

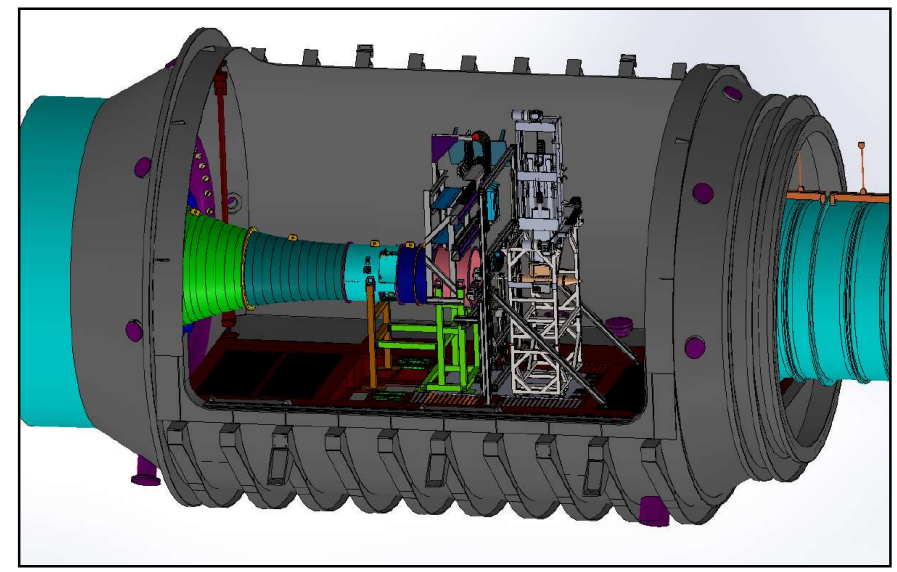

Figure 1. Solid-model image of the traversing system installation inside the PSL.

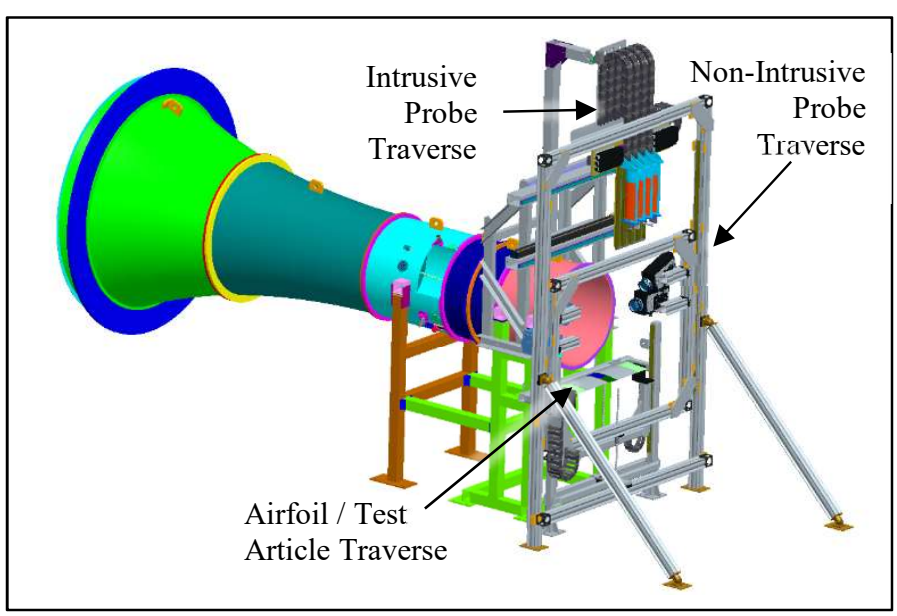

Figure 2. Solid-model image showing a closer view of the traverses for the intrusive probes, non-intrusive probes, and airfoil / test article.

Solid-model images of each separate traversing mechanism are show in Figures 3 through 6. The intrusive probe mechanism (Figure 3) allowed a survey of the upper half of the test section with the sample volumes of the probes positioned approximately $12.7 \mathrm{~cm}$ (5 inches) downstream of the duct exit plane. The intrusive probes included the
SEA Multi- Element [also known as the Multi-Wire (MW)] Probe and Ice Crystal Detector (ICD), Rearward Facing Probe (RFP), and a Rosemount Total Air Temperature (TAT) probe. Results from the ICD are not presented in this paper.

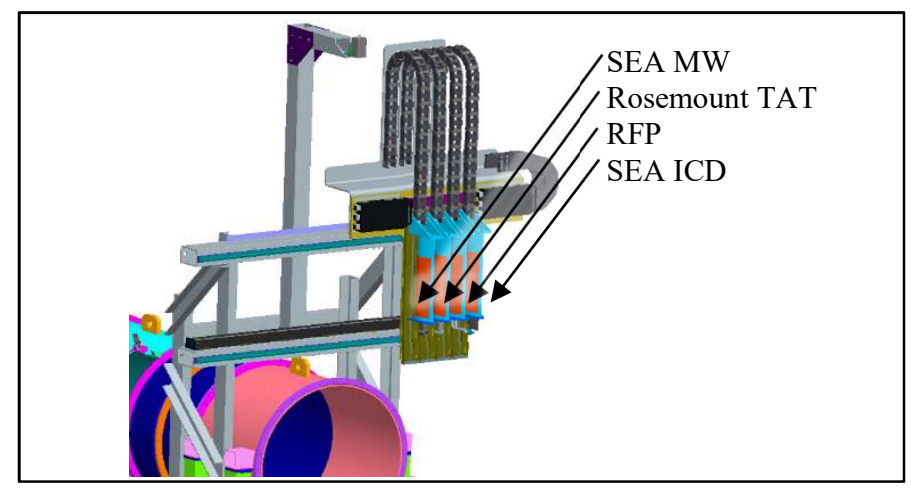

Figure 3. Solid model image showing intrusive probe traversing mechanism. The probes traversed in this test are listed in the figure.

The non-intrusive probe mechanism (Figure 4) included the Artium High Speed Imaging (HSI) and Phase Doppler Interferometer (PDI) instruments. These instruments measured the particle size distribution in a plane approximately $66 \mathrm{~cm}$ (26 inches) aft of the duct exit plane. The measurement sample volumes (approximately a small point in space) for the PDI was $1.9 \mathrm{~cm}(0.75$ inches $)$ left of the vertical duct centerline looking upstream while the HSI was $1.3 \mathrm{~cm}$ ( 0.5 inches) right of the centerline. The sample volume of both probes could traverse vertically from the horizontal duct centerline to about $22.9 \mathrm{~cm}$ (9 inches) above the centerline as seen in the figure.

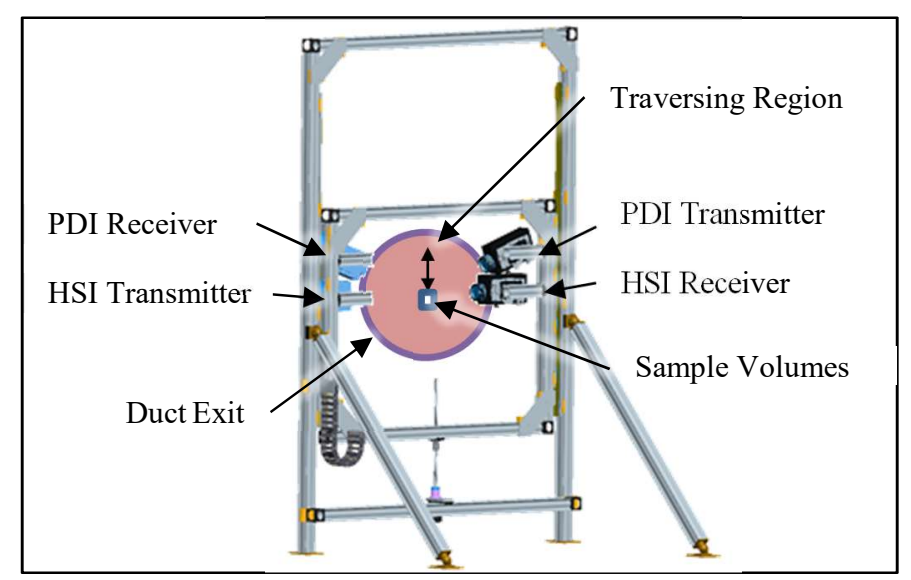

Figure 4. Solid model image showing the intrusive probe traversing mechanism. For the current test, the non-intrusive probes included the Artium HSI and PDI.

The NACA 0012 airfoil test article, which is described in more detail elsewhere [15], was moved into and out of the flow using the airfoil/test article traversing mechanism (Figure 5). The leading edge of the airfoil was approximately $12.7 \mathrm{~cm}$ (5 inches) downstream of the duct exit plane. The airfoil was nominally stowed outside of flow below the tunnel duct (as depicted in Figure 2) and was traversed into the flow centerline for ice accretion tests. The titanium airfoil center body was allowed to thermally stabilize before the ice cloud was activated by monitoring the thermocouples on the airfoil. After the ice accretion test, the airfoil was moved out of the flow to allow for deicing and cloud diagnostics. 
The Isokinetic Probe (IKP2) $[16,17]$ was traversed into and out of the flow using the traversing mechanism shown in Figure 6A. The probe was stowed above the duct at the horizontal centerline and could be traversed to any location of the duct. The probe inlet was $31.8 \mathrm{~cm}$ (12.5 inches) aft of the duct exit plane. The probe had two background humidity $(\mathrm{BH})$ inlets, one on the canister as shown in Figure 6B (BH-1), and the other on the top of the inlet as seen in Figure 6C (BH-2). The horizontal and vertical locations of the $\mathrm{BH}-1$ relative to the probe inlet was $8.9 \mathrm{~cm}$ (3.5 inches) left and $1.9 \mathrm{~cm}(0.75$ inches $)$ above, respectively. For BH-2, the vertical position was $5.7 \mathrm{~cm}(2.25$ inches) above the probe inlet but at the same horizontal location. When post-processing the data, both background humidity inlets were considered and the average value between the two used in the calculation of total water content (TWC). If a background humidity measurements became contaminated, as would occasionally occur, then that measurement was not used.

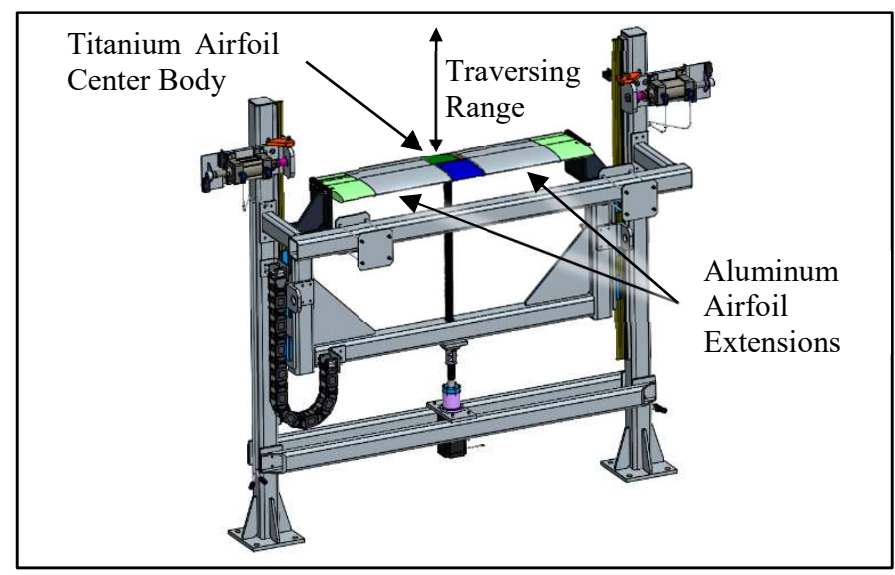

Figure 5. Solid model image showing the airfoil / test article traversing mechanism. For the current test, the airfoil test article was a NACA 0012 airfoil. The airfoil is shown in the retracted position below the duct.

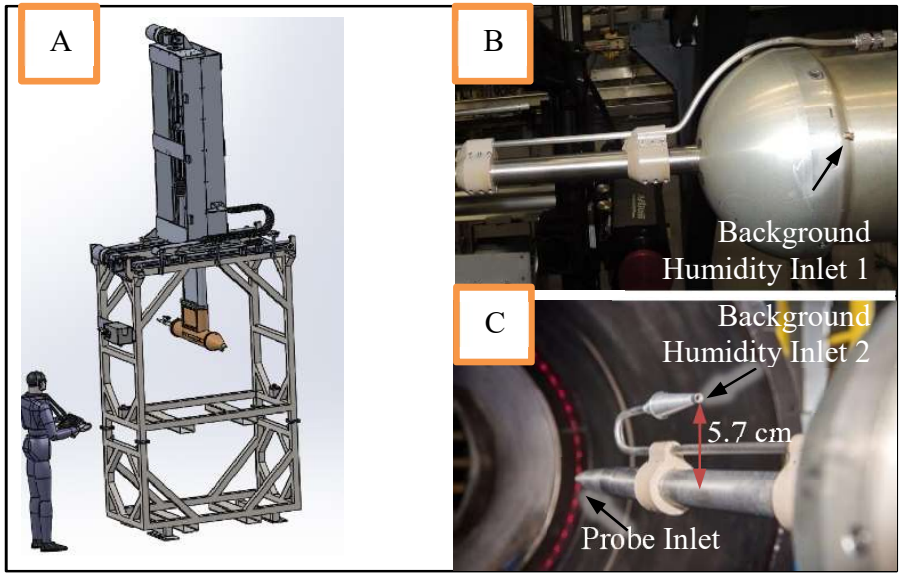

Figure 6. Solid model image showing the traversing mechanism for the isokinetic probe $(A)$ and background humidity inlets on the probe (B and $C)$. Both the probe and traversing mechanism were developed by Science Engineering Associates.

\section{Aerothermal \& Humidity Measurements}

Measurements of air temperature, pressure, and humidity were made at various locations in the plenum and at the test section. All test section values reported are centerline values. The plenum measurement results presented are averages for the duration of the spray. Measurement of temperature and humidity at the test section include both the cloud-off and cloud-on values. In some cases, the cloud-on data is reported as a change (i.e. delta, $\Delta$ ) from the cloud-off measurement. The cloud-off measurement was the 30 -second average value just prior to cloud activation. The cloud-on values were 30 second averages of the measurements just prior to cloud deactivation. Drift of the plenum conditions was accounted for by adjusting the cloud-off values by the same amount that the plenum values drifted during the spraying event.

Temperature and humidity measurements were made at the duct exit plane using a Rearward Facing Probe (RFP) [18]. In addition, a humidity measurement was made in the plenum - the inlet for this measurement was located on the upper wall of the plenum upstream of the spray bars. The temperature measurement was made using a resistive temperature device (RTD) embedded in the RFP. The humidity was measured using a SpectraSensor instrument (Model WVSS-II) which uses an optical absorbance technique on the air drawn into the RFP. An accompanying paper [13] provides further details of the RFP used in the current tests.

\section{Cloud Measurements}

The cloud measurements included $T W C$, liquid water content $(L W C$ ), and particle size distribution (PSD). The $T W C$ was measured using the IKP2 while the $L W C$ was measured using the MW probe. The PSD was measured using the Artium HSI and PDI probes. Details of the HSI and PDI techniques used to extract the PSD are described elsewhere [19].

\section{Test Conditions and Procedure}

For these tests, the mixed-phase conditions were generated by partially freezing the liquid-water droplets ejected from the spray bars. The primary parameter used to control the amount of freezing was the relative humidity in the plenum $\left(\mathrm{RH}_{0, i}\right)$. Note that total conditions exist in the plenum due to the slower moving flow. Therefore, the relative humidity is evaluated using total conditions (subscript " 0 ") in the plenum (subscript "i" for inlet plane). In these tests, $R H_{0, i}$ was varied from approximately $0 \%$ to just over $50 \%$. The humidity variations, or sweeps, occurred at four different test conditions as outlined in Table 1, although only test condition II results are reported in this paper. The total temperature $\left(T_{0}\right)$ was maintained constant for each test condition at $7.2^{\circ} \mathrm{C}\left(45^{\circ} \mathrm{F}\right)$ in the plenum. However, the flow and cloud thermally interact which required a total temperature measurement with the cloud-on, $T_{0, o n}$, using the RFP. Table 1 also shows the cloud-off static temperature $\left(T_{s}\right)$ and static pressure $\left(P_{s}\right)$ for the four primary conditions of 2018 PSL test. It is a combination $T_{s}, P_{s}$, and humidity (i.e. the wetbulb temperature) that affect the different melt ratio and $T W C$ clouds achieved and required characterization for each test condition. The individual droplets tend towards the static wet-bulb temperature $\left(\mathrm{T}_{\mathrm{wb}, \mathrm{s}}\right)$ as they travel from the spray bars to the test section. $T_{w b, s}$ is evaluated using static conditions.

The cloud was generated in the same manner as during the 2016 test [15] and only the key aspects are repeated here. A total of 22 and 19 nozzles were selected from the Standard and Mod-1 set, respectively, and the spray bar patterns remained the same for each nozzle set. The $T W C_{e, T}$ target (denoted by the subscript "T") at the duct exit plane (denoted by the subscript "e") was set to $2 \mathrm{~g} / \mathrm{m}^{3}$. The value was set by adjusting the injected water mass flow rate assuming no evaporation and uniform mixing across the center $61 \mathrm{~cm}$ (24 inch) diameter of the 
PSL exit duct. The PSD at the PSL spray bars (i.e. inlet plane) is approximated to be those measured at the NASA Icing Research Tunnel (IRT) for the same supplied water and air pressures [15]. In this paper, a particular spray PSD is referred to by the IRT median volumetric diameter and is given the subscript " $\mathrm{i}$ " to denote the inlet or spray bar plane (e.g. $M V D_{i}$ ). Since evaporation does occur for these tests and larger particles tended to concentrate near the center of the duct, the actual TWC and PSD at the test article were measured and are given the subscript "m".

Table 1. Target cloud-off test conditions. Only test condition II results are reported in this paper.

\begin{tabular}{|c|c|c|c|c|c|}
\hline $\begin{array}{c}\text { Test } \\
\text { Condition \# }\end{array}$ & $\begin{array}{c}U_{e} \\
(\mathrm{~m} / \mathrm{s})\end{array}$ & $\begin{array}{c}P_{0} \\
(\mathrm{kPa} / \mathrm{psia})\end{array}$ & $\begin{array}{c}P_{s} \\
(\mathrm{kPa} / \mathrm{psia})\end{array}$ & $\begin{array}{c}T_{0} \\
\left({ }^{\circ} \mathrm{C}\right)\end{array}$ & $\begin{array}{c}T_{s} \\
\left({ }^{\circ} \mathrm{C}\right)\end{array}$ \\
\hline I & 85 & $44.8 / 6.5$ & $42.8 / 6.21$ & 7.2 & 3.6 \\
\hline II & 135 & $44.8 / 6.5$ & $39.9 / 5.79$ & 7.2 & -1.8 \\
\hline III & 185 & $44.8 / 6.5$ & $36.0 / 5.22$ & 7.2 & -9.8 \\
\hline IV & 135 & $87.6 / 12.7$ & $78.05 / 11.32$ & 7.2 & -1.8 \\
\hline
\end{tabular}

\section{Ice Accretion Image Analysis Method}

The video image analysis method has been described in detail previously $[15,20,21]$. The same image analysis methods were used to document ice accretions in the present study.

\section{Results}

The results are divided into test condition and ice accretion sections. The test condition section is further divided into aerothermal and cloud subsections. For this paper, only the results from test condition II are presented.

\section{Test Section Conditions}

The conditions at the duct exit plane of PSL (denoted with the subscript "e") represent the conditions at the accretion site.

\section{Aerothermal Conditions}

The changes in humidity and total air temperature between cloud-on and cloud-off conditions at the test section centerline as a function of $R H_{0, i}$ (plenum humidity) are presented in Figure 7. This figure presents humidity data as changes in mass-mixing ratio at the test section $\left(\Delta M M R_{e}\right)$. The $M M R$ is the ratio of the vapor to dry-air mass. The humidity data in Figure 7 come from the RFP and IKP2 BH. This figure shows that increasing $R H_{0, i}$ suppresses evaporation resulting in smaller humidity changes at the test section when the cloud comes on. Correspondingly, there is less evaporative cooling with increasing $R H_{0, i}$ resulting in smaller changes in total temperature at the exit $\left(\Delta T_{e}\right)$, as can also be seen shown on the right axis of Figure 7. An accompanying paper [13] provides further details on the reduction of data from the RFP.

\section{Cloud Conditions}

This section presents the measured PSD, $L W C$, and $T W C$. The PSD measurements for test condition II at four different relative humidity values are shown in Table 2 . The table shows the various percentile cumulative volume diameters $\left(d_{v}\right)$ and includes the IRT values for the same spray bar settings used in the test. The spray bar settings corresponded to a $20 \mu \mathrm{m} \mathrm{MVD}$ cloud at IRT which is approximated to exist in the plenum prior to any evaporation. At PSL, the measured Page 4 of 11 particle sizes were larger than IRT presumably due to the smallest particles evaporating away although the final distributions did not signicantly vary with the different plenum relative humidity values.

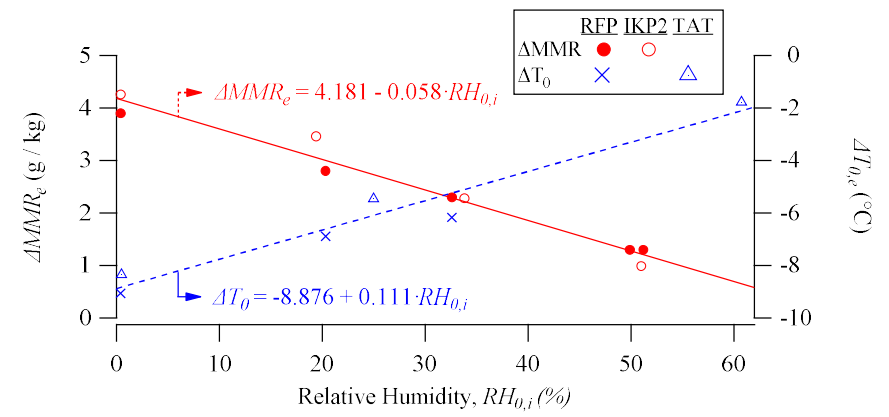

Figure 7. Humidity and air temperature changes at the test section centerline as a function plenum relative humidity.

Table 2. Select particle distribution measurement values for test condition II at 5 different plenum humidity values. For comparison, the IRT values at the same spray bar settings are included in the table.

\begin{tabular}{|c|c|c|c|c|c|c|}
\hline $\boldsymbol{R H}_{\boldsymbol{P L}}$ & $\boldsymbol{d}_{\boldsymbol{v 0 . 1 0}}$ & $\boldsymbol{d}_{\boldsymbol{v} 0.25}$ & $\boldsymbol{d}_{\boldsymbol{v} 0.5 \boldsymbol{0}}$ & $\boldsymbol{d}_{\boldsymbol{v} 0.75}$ & $\boldsymbol{d}_{\boldsymbol{v} 0.90}$ & $\boldsymbol{d}_{\boldsymbol{v} 0.99}$ \\
\hline $\boldsymbol{\%}$ & $\boldsymbol{\mu m}$ & $\boldsymbol{\mu m}$ & $\boldsymbol{\mu m}$ & $\boldsymbol{\mu m}$ & $\boldsymbol{\mu m}$ & $\boldsymbol{\mu m}$ \\
\hline $\mathbf{I R T}$ & 9 & 12 & 20 & 33 & 48 & 99 \\
\hline $\mathbf{0 . 6}$ & 18 & 25 & 36 & 52 & 71 & 104 \\
\hline $\mathbf{1 9 . 6}$ & 19 & 26 & 36 & 53 & 74 & 112 \\
\hline $\mathbf{3 2 . 8}$ & 18 & 25 & 35 & 49 & 68 & 100 \\
\hline $\mathbf{4 9 . 6}$ & 17 & 24 & 33 & 48 & 67 & 99 \\
\hline
\end{tabular}

For water content, the data presented are averages of the instantaneous water content measurements during stable portions of the spray. Averages are used since the $T W C$ and $L W C$ signals tend to fluxtuate about a mean value under steady state conditions. Figure 8 shows the $T W C$ and $L W C$ averages as a function of $R H_{0, i}$ for test condition II. The figure shows measurements from the IKP2 and the three heated elements $(2.1-\mathrm{mm}, 0.5-\mathrm{mm}$, and a half-pipe, HP, which is a $2.1-\mathrm{mm}$ scoop) of the MW probe [22]. All data of the MW is presented although only the results of the 2.1-mm wire and IKP2 results are used in the analysis, as explained later. The IKP2 and MW measurements were taken at different times and with different resolution in $R H_{0, i}$. The IKP2 data was generally linear with $R H_{0, i}$ and a curve fit, shown in Figure 8, was used to interpolate $T W C$ values in between measured points. Recall that the injected water mass flow was set to produce a $2 \mathrm{~g} / \mathrm{m}^{3}$ cloud if distributed uniformly across the center $61-\mathrm{cm}$ (24-inch) diameter area without evaporation. The resulting measurements show water contents above $2 \mathrm{~g} / \mathrm{m}^{3}$ even under conditions where significant evaporation is occurring (i.e. $R H_{0, i}=0 \%$ ). These elevated $T W C$ measurements suggest that the water is concentrating more at the centerline.

The ratio of the $L W C$ to $T W C$ is the melt ratio, $\eta_{M R}$, and details of this calculation have been previously describe [15]. The equations, (1) - (3), are repeated below for clarity. The $L W C$ is calculated from the 2.1-mm element, where the subscript denotes the particular wire $\left(L W C_{m, 2.1}\right)$ of the MW probe while the $T W C$ comes directly from the IKP2 $\left(T W C_{m, I K P 2}\right)$. For equation (3) related to the MW, the collision efficiency $(C E)$ is the percentage of the upstream particle mass colliding with the particular hot-wire, the water-catch efficiency $(W E)$ is the percentage of collected water that is evaporated by the hot wire, 
and the false response $(F R)$ is the signal on the liquid water elements due to ice crystals.

$$
\begin{gathered}
\eta_{M R}=\frac{L W C}{T W C}=\frac{L W C}{L W C+I W C} \\
T W C_{m, I K P 2}=T W C=L W C+I W C \\
L W C_{m, 2.1}=C E_{2.1}\left(W E_{2.1} \cdot L W C+F R_{2.1} \cdot I W C\right)
\end{gathered}
$$

For equation (3), the $C E_{2.1}$ was calculated from literature data [23, 24] to be $\sim 97.6 \%$ using the test flow conditions and the $d_{v 50}$ data from Table 2. The PSD variations in Table 2 had less than $1 \%$ effect on the calculation of $C E_{2.1}$. The value for $W E_{2.1}$ was calculated to be $59.1 \%$ from the data in Figure 8. The value for $F R_{2.1}$ was calculated to be $6.2 \%$ using data (not presented) at the same flow and PSD but significantly colder air temperatures where the cloud was expected to be fully glaciated. Using equations (1) - (3), the calculated values of $\eta_{\text {MR }}$ are plotted in Figure 8. The results show that the cloud transitioned from glaciated to liquid conditions as $R H_{0, i}$ increased.

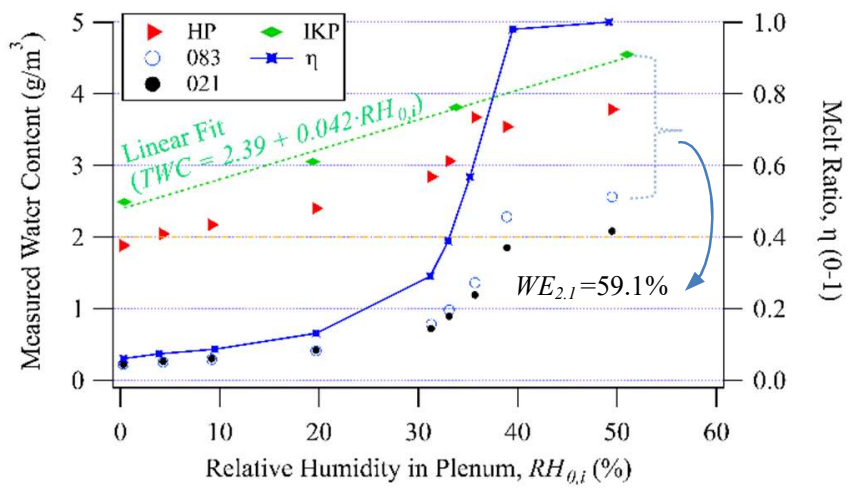

Figure 8. Measured water contents as a function of plenum relative humidity for test condition II. The figure includes the calculated water catch efficiency, WE, for the 2.1-mm wire at this test condition.

\section{Ice Accretion Characteristics}

This paper presents ice accretion measurements for test condition II at a zero-degree angle-of-attack. The accretions were generated at different $\mathrm{RH}_{0, i}$ along the transition from mostly glaciated to more liquid cloud conditions. Attempts were made to study accretions at low, mid, and high $\eta_{\mathrm{MR}}$. The specific $R H_{0, i}$ where ice accretions were studied is shown in Table 3. The table also lists the data acquisition number from the PSL facility (i.e. the Escort file number) corresponding to each test. The cases will be referred to by the letter as defined in Table 3 .

The test conditions for each accretion case are shown in Tables 4 through 6 . The second row in each table indicates the source of the data. Table 4 shows the cloud conditions for the accretion cases including the $T W C_{e}$ and $\eta_{M R, e}$. These values were calculated by interpolating the data from Figure 8 using the $\mathrm{RH}_{0, i}$ for each accretion case. The temperature and humidity conditions for each accretion case are shown in Table 5 and 6 , respectively. The temperature at the accretion site was calculated by adding the interpolated $\Delta T_{0}$ from Figure 7 to the measured average total temperature in the plenum, $T_{0, i}$ (or TPL) during the accretion. The humidity values were calculated similarly, namely that the plenum humidity, $M M R_{i}$, was adjusted based on the interpolated $\triangle M M R$ from Figure 7. Tables 4 through 6 show that it was not possible in the present experimental setup to vary $\eta_{M R, e}$ independently of test section $T W C$, temperature, and humidity since

\begin{tabular}{|c|c|c|c|c|c|c|}
\hline $\begin{array}{c}\text { Test } \\
\text { Cond } \\
\#\end{array}$ & $U_{e}$ & $\begin{array}{c}P_{0} \\
\mathrm{kPa} \\
\text { (psia) }\end{array}$ & $T_{0}$ & Case & $R H_{P L}$ & $\begin{array}{c}\text { Escort } \\
\text { File } \\
\#\end{array}$ \\
\hline \multirow{4}{*}{ II } & \multirow{4}{*}{133} & \multirow{4}{*}{$\begin{array}{l}44.8 \\
(6.5)\end{array}$} & \multirow{4}{*}{$\begin{array}{c}\text { See } \\
\text { Table } 5\end{array}$} & $\mathrm{a}$ & 20.6 & 170 \\
\hline & & & & b & 25.2 & 593 \\
\hline & & & & c & 30.2 & 171 \\
\hline & & & & d & 34.5 & 169 \\
\hline
\end{tabular}
these also varied with $\mathrm{RH}_{0, i}$.

Table 3. Ice accretion test matrix summary (measured values)

Table 4. Test cloud conditions

\begin{tabular}{|c|c|c|c|}
\hline Case & $\begin{array}{c}R H_{0, i} \\
(\%)\end{array}$ & $\begin{array}{c}T W C_{e} \\
\left(\mathrm{~g} / \mathrm{m}^{3}\right)\end{array}$ & $\begin{array}{c}\eta_{M R, e} \\
(\text { dimensionless })\end{array}$ \\
\hline Source $\rightarrow$ & Measurement & Fig. 8 & Fig.8 \\
\hline $\mathrm{a}$ & 20.6 & 3.3 & 0.14 \\
\hline $\mathrm{b}$ & 25.2 & 3.4 & 0.21 \\
\hline $\mathrm{c}$ & 30.2 & 3.7 & 0.28 \\
\hline $\mathrm{d}$ & 34.5 & 3.8 & 0.51 \\
\hline
\end{tabular}

Table 5. Test temperatures conditions

\begin{tabular}{|c|c|c|c|c|c|c|}
\hline Case & $\begin{array}{c}T_{0, i}(=T P L) \\
\left({ }^{\circ} \mathrm{C}\right)\end{array}$ & $\begin{array}{c}\Delta T_{0} \\
\left({ }^{\circ} \mathrm{C}\right)\end{array}$ & $\begin{array}{c}T_{0, e} \\
\left({ }^{\circ} \mathrm{C}\right)\end{array}$ & $\begin{array}{c}T_{s, e} \\
\left({ }^{\circ} \mathrm{C}\right)\end{array}$ & $\begin{array}{c}T_{w b, 0, e} \\
\left({ }^{\circ} \mathrm{C}\right)\end{array}$ & $\begin{array}{c}T_{w b, s, e} \\
\left({ }^{\circ} \mathrm{C}\right)\end{array}$ \\
\hline Source $\rightarrow$ & Meas. & $\begin{array}{c}\text { Fig. } \\
7\end{array}$ & Calc. & Calc. & Calc. & Calc. \\
\hline $\mathrm{a}$ & 7.1 & -6.6 & 0.5 & -8.3 & -2.6 & -6.8 \\
\hline $\mathrm{b}$ & 7.3 & -6.1 & 1.2 & -7.6 & -1.9 & -6.0 \\
\hline $\mathrm{c}$ & 7.6 & -5.5 & 2.1 & -6.8 & -1.1 & -5.1 \\
\hline $\mathrm{d}$ & 7.2 & -5.1 & 2.2 & -6.6 & -0.8 & -4.7 \\
\hline
\end{tabular}

Table 6. Test humidity conditions

\begin{tabular}{|c|c|c|c|}
\hline Case & $\begin{array}{c}M M R_{i} \\
(\mathrm{~g} / \mathrm{kg})\end{array}$ & $\begin{array}{c}\Delta M M R \\
(\mathrm{~g} / \mathrm{kg})\end{array}$ & $\begin{array}{c}M M R_{e} \\
(\mathrm{~g} / \mathrm{kg})\end{array}$ \\
\hline Source $\rightarrow$ & Meas. & Fig. 7 & Calc. \\
\hline $\mathrm{a}$ & 2.9 & 3.0 & 5.9 \\
\hline $\mathrm{b}$ & 3.6 & 2.7 & 6.3 \\
\hline $\mathrm{c}$ & 4.4 & 2.4 & 6.8 \\
\hline $\mathrm{d}$ & 4.9 & 2.2 & 7.1 \\
\hline
\end{tabular}

Table 5 includes calculated wet-bulb temperatures both at total $\left(T_{w b, 0, e}\right)$ and static conditions $\left(T_{w b, s, e}\right)$. These calculations use the humidity values $M M R_{e}$ from Table 6. An interesting observation is that the calculated $T_{w b, 0, e}$ is cooler than the total temperature while $T_{w b, s, e}$ is warmer than static temperature. The explanation for this is that the water vapor saturation temperature corresponding to the measured humidity is between the total and static temperatures. When the humidity is below saturation, evaporation occurs using energy resulting in a calculated wet bulb that is below the dry bulb temperature. However, when the humidity exceeds saturation, condensation occurs resulting in heat being deposited and a calculated wet-bulb that is warmer than the dry bulb temperature.

Figures 10 through 13 show results from each accretion case studied in this paper. Each figure contains images of ice accretions and 
analysis results. The images are of the ice shapes at select times during the accretion process (typically 60, 180, 300, and 600 seconds after the start of the spray). The images are from a span view camera (left columns, images A-D) and side-profile view camera (left center columns, images E-H). In each figure, there is an Ice Shape Analysis Graph (upper right, image I) extracted from the side-profile. The shadow region denoted in image I represents the minimum ice thickness which can be measured. This minimum is due to a perspective blind spot of the imaging system. Figures 10 through 13 also show a Surface Temperature and Ice Growth Rate Graph (lower right graph, image J). There are five surface temperature measurements presented (left axis, image J) with the first three thermocouple locations depicted in image I. The remaining thermocouples, TC13 and TC14, are located at $\mathrm{X}=80.39 \mathrm{~mm}$ and $\mathrm{Y}=16.00 \mathrm{~mm}$ and at $\mathrm{X}=139.07 \mathrm{~mm}$ and $\mathrm{Y}=13.74 \mathrm{~mm}$, respectively. See Figure 4 in reference [15] for a full definition of thermocouple locations. The ice growth (rightmost axis in image $J$ ) is measured at the centerline of the titanium airfoil using the span view camera data. Linear curve fits of the ice thickness $(t)$ versus time, or ice growth rates, during select intervals are provided in Table 7. The purpose of presenting this information is to provide data against which to compare models of ice crystal icing.

Table 7. Measured ice growth rates during select time intervals for Cases (a) - (d).

\begin{tabular}{|c|c|c|c|}
\hline $\begin{array}{c}\text { Case / Escort } \\
\text { Number }\end{array}$ & $\begin{array}{c}\text { Time } \\
\text { Interval (s) }\end{array}$ & $\begin{array}{c}\text { Interval } \\
\text { Duration } \\
\text { (s) }\end{array}$ & $\begin{array}{c}\text { Growth } \\
\text { Rate }(\mathrm{mm} / \mathrm{s})\end{array}$ \\
\hline (a) 170 & $0-100$ & 101 & 0.000 \\
& $120-499$ & 380 & 0.004 \\
\hline & $0-10$ & 11 & 0.194 \\
(b) 593 & $11-150$ & 140 & 0.000 \\
& $151-615$ & 465 & 0.013 \\
\hline & $0-12$ & 13 & 0.000 \\
(c) 171 & $13-35$ & 23 & 0.086 \\
& $36-239$ & 204 & 0.013 \\
& $240-609$ & 370 & 0.069 \\
\hline & $0-19$ & 20 & 0.000 \\
(d) 169 & $20-35$ & 16 & 0.091 \\
& $36-307$ & 272 & 0.015 \\
& $308-636$ & 329 & 0.081 \\
\hline
\end{tabular}

Figure 10 shows the ice accretion for Case (a), which had an $\eta_{M R, e}$ of 0.14 and was the lowest melt ratio accretion test at this condition. In this case, there was only a small accretion ( $\sim 2 \mathrm{~mm}$ thickness) on the titanium airfoil center body after 500 seconds of cloud exposure (Figure 10J). Table 7 shows the growth rate to $0.004 \mathrm{~mm} / \mathrm{s}$. In addition, there was some accretion visible on the aluminum extensions (see Figures $10 \mathrm{C} \& \mathrm{G})$. In this case, the accretion started at the leading edge of the aluminum airfoil extension and was loosely adhered. Once reaching an appreciable size, the aerodynamic forces pushed the accretion to the top of the airfoil where it anchored for a period of time before shedding away. The accretions on the aluminum airfoil extensions, although presented on the Ice Shape Analysis Graph (Figure $10 \mathrm{I}$ ), should not be considered for ice accretion code development since the impinging cloud and surface conditions are not well characterized beyond the titanium airfoil center body. Finally, the thermocouple data (Figure $10 \mathrm{~J}$ ) shows that all the surface temperatures decrease to below freezing temperatures although at different rates due to the thermal inertia of the airfoil. Generally, the thermocouples nearest the leading edge equilibrate faster than those downstream. The leading edge thermocouple, TC03, measures approximately $0^{\circ} \mathrm{C}$ shortly after spray initiation staying at this value for $\sim 30$ seconds before cooling to $-0.5^{\circ} \mathrm{C}$ which is warmer than the
$T_{w b, 0, e}$ value of $-2.8^{\circ} \mathrm{C}$ calculated in Table 5. It would be expected that the leading edge temperature of the airfoil approach the total wet-bulb temperature $\left(T_{w b, 0, e}\right)$ with a small presence of liquid due to evaporative cooling. However, the temperature of liquid water and ice mixture (presumably near $0^{\circ} \mathrm{C}$ ) as well as heat transfer into the airfoil may explain why the total wet-bulb temperature was not achieved at the leading edge. Interestingly, TC06 did measure exactly the value of the total wet bulb temperature of $-2.8^{\circ} \mathrm{C}$ suggesting that some evaporation is occurring from the surface at this location.

Figure 11 shows the ice accretion for Case (b), which had a $\eta_{M R, e}$ of 0.21 at this condition. In this case, the ice thickness initially grew to approximately $1.7 \mathrm{~mm}$ within the first 10 seconds and remained at this thickness until 150 seconds (Figure $11 \mathrm{~J}$ - gray line labelled " $\mathrm{t}$ "). Subsequently, the ice began to grow in a linear fashion reaching 7.6 $\mathrm{mm}$ at 615 seconds (growth rate $\sim 0.013 \mathrm{~mm} / \mathrm{s}$ per Table 7) when the test was ended. The ice shape was pointed and devoid of feather features which is indicative of significant erosion. A shadow of the ice particle debris field is visible in the side-profile view camera images (Figures $11 \mathrm{G} \& \mathrm{H}$ ). Figure $11 \mathrm{~J}$ shows that the leading edge thermocouple (TC03) reached $0^{\circ} \mathrm{C}$ just 7 seconds after the spray initiation and remained at this temperature for 120 seconds. Subsequently, TC03 began to decrease reaching $-1.1^{\circ} \mathrm{C}$ at the end of the test. In this case, the $T_{w b, 0, e}$ is calculated to be $-1.9^{\circ} \mathrm{C}$ so again the leading edge temperatures are slightly warmer than the calculated total wet bulb temperature.

Figure 12 shows the ice accretion for Case (c), which had an $\eta_{M R, e}$ of 0.28 at this condition. Compared to Case (b), the ice shape was more substantial in terms of size reaching just over $30 \mathrm{~mm}$ thickness at the leading edge at the end of the test (Figure $12 \mathrm{~J}$ - see gray line labelled "t"). Furthermore, the final ice shape has more thickness perpendicular to the chord with rough, feather-like features downstream of a smoother and pointed leading edge. It is recommended that modelling comparisons be limited to the smoother leading edge regions as the downstream feather-like features seen in Figure $12 \mathrm{G} \& \mathrm{H}$ can be anywhere along the span of the airfoil and represent a maximum-thickness combined cross section. Occasionally, asymmetrical ice shapes and/or feathers appeared due to ice forming on the airfoil extensions which then shifted to one side of the airfoil due to aerodynamic forces - one such example can be seen in Figure $12 \mathrm{H}$ where an asymmetric feather appears below the airfoil. The thermocouple data for Case (c) (Figure $12 \mathrm{~J}$ ) shows that the leading edge reached $0{ }^{\circ} \mathrm{C}$ quickly (within 6 seconds) and remained at this value for about 400 seconds after which it showed a slow cooling trend. As the ice thickness grew, the thermocouple became further removed from the impinging flow but thermal conduction into the metal surface may still have played a role as suspected in this case. The other thermocouples all reached several degrees below freezing, similar to Cases (a) and (b). However, the temperature data showed several inflection points in TC06 and TC10 which require further analysis and interpretation to explain. Furthermore, the leading edge ice growth (Figure 13J, gray line) had several inflection points resulting in four different leading-edge growth rate regimes as shown in Table 7. Closer inspection of Figures $12 \mathrm{~B}$ and $\mathrm{F}$ shows that ice growth initiated downstream of the leading edge both above and below the airfoil and propagated upstream. It was not until after these upper and lower growths reached the leading edge and merged that there was significant leading edge growth which began at 240 seconds after spray initiation and continued until the end of the test over 360 seconds later.

Figure 13 shows the ice accretion for Case (d), which had an $\eta_{M R, e}$ of 0.51 at this condition. Of all the cases studied in this paper, Case (d) 
had the largest size accretion reaching a leading edge thickness of $33.5 \mathrm{~mm}$ (Figure $13 \mathrm{~J}$, gray line). In addition, this case had the largest growth rates measured reaching $0.081 \mathrm{~mm} / \mathrm{s}$ for the second half of the test (Table 7). Qualitatively, the growth rate and temperature trends for Case (d) resemble Case (c). This includes that the faster ice growth initiated aft of the leading edge and then propagated forward.

\section{Discussion}

There are four primary points to discuss regarding the results of this paper. The first is that small changes in plenum relative humidity can produce large changes in melt ratio at the test section. Starting at a plenum relative humidity of $20 \%$ resulted in a melt ratio of 0.14 . Increasing the relative humidity in $5 \%$ consecutive increments resulted in melt ratios of $0.21,0.28$, and 0.51 , respectively. There is a delicate balance between convective and evaporative cooling that is a function of the several factors such as tunnel speed, temperature, pressure, relative humidity and particle size distribution that ultimately dictates the resulting cloud melt ratio at the tunnel exit.

The second point is that it is not possible in the present experimental setup to vary melt ratio independently of other parameters at the test section by just varying plenum relative humidity. This includes parameters like total water content, total temperature, and wet-bulb temperature since they are also a functions of the plenum relative humidity. For the cases presented, and despite the same amount of cloud spray being injected into the facility, the measured total water content increased by $\sim 15 \%$ for the highest plenum humidity compared with the lowest due to decreased evaporation. However, the total temperature variation was only $\sim 2^{\circ} \mathrm{C}$ for the cases presented.

The third discussion point is that the different melt fractions resulted in different ice shapes particularly when comparing Case (b) to Cases (c) and (d), the latter two showing qualitatively similar characteristics. The lower melt ratio cases appeared smaller, smooth, pointy, and devoid of feathers. The higher melt ratio cases were generally larger than lower melt ratio cases and did have some rougher, feather-like features downstream of the leading edge. Furthermore, the steady-state growth rates (i.e. those after the initial transients) were still increasing at the maximum melt ratios tested (Figure 9). This result is contrary to other tests using different test articles reported in the literature which produced ice shapes which stopped growing (i.e. steady-state shapes) despite continuous exposure to the cloud $[4,25]$.

Finally, in ice crystal icing, there is a general acceptance that a minimum and maximum melt ratio exists for accretion to occur. The minimum limit is described as the limit below which too little melt occurs preventing the ice to stick and the ice crystals simply bounce off the surface without accreting, or the impinging ice crystals erode away any accreted ice. The maximum limit is described as the limit above which there is too much melt and the impinging ice and water mixture washes away without accreting. Earlier data (e.g. [4]) suggests that, in between these limits, aggressive growth is possible. That region is termed a plateau region since variations in melt ratio do not significantly affect the growth rate. Figure 9 plots the growth rate data as a function of $\eta_{M R, e}$ using the data from this experiment. For the higher $\eta_{M R, e}$ cases, there are two growth rates shown: one earlier in the test and the other later in the test. The data in Figure 9 supports the existence of a minimum melt ratio limit and plateau region. However, the maximum melt ratio limit was not reached for these tests. The maximum melt ratio limit requires that the liquid water does not supercool. In the present experiments it is possible that the liquid water was supercooled either due to subfreezing wet-bulb temperatures on airfoil or due to the presence of supercooled water droplets impinging on the airfoil. The latter possibility is inferred since recent modelling work [26-28] indicates that the water droplets approach the static wetbulb temperature which were below freezing for all the cases in the present experiment. However, it is not clear if the water droplets were supercooling since the water used during the tests was non-deionized tap water which helps promote freeze-out. Should the liquid portion of the cloud be supercooling then a maximum melt ratio limit may not be reached in the current experiments. Further investigation is required to understand if the cloud was supercooling and to what degree.

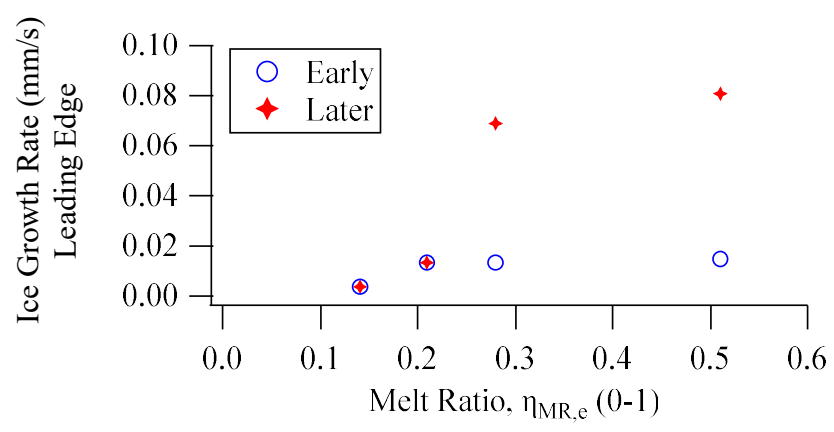

Figure 9. This figure shows the ice growth rates at the leading edge versus melt ratio. The blue symbols show the growth rate early in the test. The red symbols are from the latter parts of the same test where the growth rate accelerated at the leading edge for the higher melt ratio cases.

\section{Summary/Conclusions}

This paper describes an ice-crystal icing experiment conducted at the NASA Propulsion System Laboratory during June 2018. This test produced ice shape data on an airfoil at four different melt ratios for otherwise the same aero-thermal conditions and particle size distribution in an upstream plenum. The different melt ratios were achieved by varying the plenum relative humidity which changed the amount of evaporative cooling. Despite being at the same plenum conditions, except for the relative humidity in the plenum, the test section total water content, particle size distribution, total and wet-bulb temperatures varied at the test section to different degrees due to the different amounts of evaporation from the cloud. The test section conditions were measured using a newly developed instrument traverse system which is also described in the paper. The test conditions - as well as key ice accretion data like 2D ice shape, growth rate, and surface temperature - are documented in the paper for the purpose of developing and validating ice-crystal accretion models. The accretions presented support a minimum melt ratio threshold to allow accretion and the existence of a plateau region where there is aggressive ice accretion as described by previous research. However, a maximum melt ratio limit was not observed during the current tests and are complicated by a possibility that the liquid portions of the water may have supercooled. Furthermore, no steady-state ice shapes were observed during the present testing.

\section{References}

[1] Mason, J. G., Strapp, J. W., and Chow, P., "The Ice Particle Threat to Engines in Flight," American Institute of Aeronautics and Astronautics, AIAA-2006-206, 2006, doi:10.2514/6.2006-206.

[2] Flegel, A. B., "Ice Crystal Icing Research at NASA Glenn Research Center," American Institute of Aeronautics and Astronautics, 2017, doi: 10.2514/6.2017-4085. 
[3] Wright, W. B., Jorgenson, P. C. E., and Veres, J. P., "Mixed Phase Modeling in GlennICE with Application to Engine Icing," American Institute of Aeronautics and Astronautics, AIAA-20107674, 2010, doi:10.2514/6.2010-7674

[4] Currie, T. C., Fuleki, D., and Mahallati, A., "Experimental Studies of Mixed-Phase Sticking Efficiency for Ice Crystal Accretion in Jet Engines," American Institute of Aeronautics and Astronautics, AIAA-2014-3049, 2014, doi:10.2514/6.2014-3049.

[5] Villedieu, P., Trontin, P., and Chauvin, R., "Glaciated and mixed phase ice accretion modeling using ONERA 2D icing suite," American Institute of Aeronautics and Astronautics, AIAA-20142199, 2014, doi:10.2514/6.2014-2199.

[6] Wright, W., Struk, P., Bartkus, T. P., and Addy, G., "Recent Advances in the LEWICE Icing Model," SAE, SAE Technical Paper 2015-01-2094, 2015, doi:10.4271/2015-01-2094.

[7] Griffin, T. A., Lizanich, P., and Dicki, D. J., "PSL Icing Facility Upgrade Overview," American Institute of Aeronautics and Astronautics, AIAA-2014-2896, 2014, doi:10.2514/6.2014-2896.

[8] Oliver, M. J., "Validation Ice Crystal Icing Engine Test in the Propulsion Systems Laboratory at NASA Glenn Research Center," American Institute of Aeronautics and Astronautics, AIAA-20142898, 2014, doi: 10.2514/6.2014-2898.

[9] Oliver, M., "Ice Crystal Icing Engine Testing in the NASA Glenn Research Center's Propulsion Systems Laboratory: Altitude Investigation," SAE Int. J. Aerosp, 8(1), p. 5, 2015, doi:10.4271/2015-01-2156.

[10] Flegel, A. B., and Oliver, M. J., "Preliminary Results from a Heavily Instrumented Engine Ice Crystal Icing Test in a Ground Based Altitude Test Facility," American Institute of Aeronautics and Astronautics, AIAA-2016-3894, 2016, doi:10.2514/6.20163894.

[11] Anderson, D. N., 2004, "Manual of Scaling Methods."

[12] Poinsatte, P. E., Van Fossen, G. J., Newton, J. E., and De Witt, K. J., "Heat transfer measurements from a smooth NACA 0012 airfoil," J Aircraft, 28(12), pp. 892-898, 1991, doi: $10.2514 / 3.46114$.

[13] Agui, J. H., Struk, P. M., and Bartkus, T. P., "Total Temperature Measurements in Icing Cloud Flows using a Rearward Facing Probe," SAE Technical Paper, 2019, doi:to appear.

[14] Bartkus, T. P., Tsao, J. C., and Struk, P. M., "Analysis of Experimental Ice Accretion Data and Assessment of a Thermodynamic Model During Ice Crystal Icing " SAE Technical Paper, 2019, doi:to appear.

[15] Struk, P. M., Ratvasky, T. P., Bencic, T., Van Zante, J. F., et al., "An Initial Study of the Fundamentals of Ice Crystal Icing Physics in the NASA Propulsion Systems Laboratory," American Institute of Aeronautics and Astronautics, AIAA-2017-4242, 2017, doi: $10.2514 / 6.2017-4242$.

[16] Strapp, J. W., Lilie, L. E., Ratvasky, T. P., Davison, C. R., et al., "Isokinetic TWC Evaporator Probe: Development of the IKP2 and Performance Testing for the HAIC-HIWC Darwin 2014 and Cayenne Field Campaigns," American Institute of Aeronautics and Astronautics, AIAA-2016-4059 and NASA TM-2016-219151, 2016, doi: $10.2514 / 6.2016-4059$.

[17] Davison, C. R., Strapp, J. W., Lilie, L. E., Ratvasky, T. P., et al., "Isokinetic TWC Evaporator Probe: Calculations and Systemic Error Analysis," American Institute of Aeronautics and Astronautics, AIAA-2016-4060, 2016, doi:10.2514/6.2016-4060.

[18] Agui, J. H., Struk, P. M., and Bartkus, T. P., "Total Temperature Measurements Using a Rearward Facing Probe in Supercool Liquid Droplet and Ice Crystal Clouds," American Institute of Aeronautics and Astronautics, AIAA-2018-3970, 2018, doi: $10.2514 / 6.2018-3970$.

[19] King, M. C., Manin, J., Van Zante, J. F., Timko, E. N., et al., "Particle Size Calibration Testing in the NASA Propulsion System

Page 8 of 11
Laboratory," American Institute of Aeronautics and Astronautics, AIAA-2018-3971, 2018, doi:10.2514/6.2018-3971.

[20] Struk, P. M., King, M. C., Bartkus, T. P., Tsao, J.-C., et al., "Ice Crystal Icing Physics Study using a NACA 0012 Airfoil at the National Research Council of Canada's Research Altitude Test Facility," American Institute of Aeronautics and Astronautics, AIAA-2018-4224, 2018, doi:10.2514/6.2018-4224.

[21] Struk, P. M., Bartkus, T. P., Tsao, J. C., Currie, T., et al., "Ice Accretion Measurements on an Airfoil and Wedge in Mixed-Phase Conditions," SAE, SAE Technical Paper 2015-01-2116, 2015, doi: 10.4271/2015-01-2116.

[22] Lilie, L., Emery, E., Strapp, J. W., and Emery, J., "A Multiwire Hot-Wire Device for Measurment of Icing Severity, Total Water Content, Liquid Water Content, and Droplet Diameter " American Institute of Aeronautics and Astronautics, AIAA-2005-859, 2005, doi:10.2514/6.2005-859.

[23] Rigby, D. L., Struk, P. M., and Bidwell, C. S., "Simulation of fluid flow and collection efficiency for an SEA multi-element probe," American Institute of Aeronautics and Astronautics, AIAA-20142752, 2014, doi:10.2514/6.2014-2752.

[24] Struk, P. M., Rigby, D. L., and Venkataraman, K., "A Thermal Analysis of a Hot-Wire Probe for Icing Applications," American Institute of Aeronautics and Astronautics, AIAA-2014-2331, 2014, doi: $10.2514 / 6.2014-2331$.

[25] Currie, T. C., and Fuleki, D., "Experimental Results for Ice Crystal Icing on Hemispherical and Double Wedge Geometries at Varying Mach Numbers and Wet Bulb Temperatures," American Institute of Aeronautics and Astronautics, AIAA-2016-3740, 2016, doi: $10.2514 / 6.2016-3740$.

[26] Bartkus, T. P., Struk, P. M., and Tsao, J. C., "Comparisons of Mixed-Phase Icing Cloud Simulations with Experiments Conducted at the NASA Propulsion Systems Laboratory," American Institute of Aeronautics and Astronautics, 2017, doi:10.2514/6.2017-4243.

[27] Bartkus, T. P., Struk, P. M., and Tsao, J. C., "Development of a Coupled Air and Particle Thermal Model for Engine Icing Test Facilities," SAE Int. J. Aerosp., 8(1), p. 18, 2015, doi: 10.4271/2015-01-2155.

[28] Bartkus, T. P., Struk, P. M., Tsao, J. C., and Van Zante, J. F., "Numerical Analysis of Mixed-Phase Icing Cloud Simulations in the NASA Propulsion Systems Laboratory," American Institute of Aeronautics and Astronautics, AIAA-2016-3739, 2016, doi: $10.2514 / 6.2016-3739$.

\section{Acknowledgments}

The authors wish to acknowledge the financial support for this work by the Advanced Aircraft Icing (AAI) subproject of the NASA Advanced Air Transport Technology Project (AATT) under NASA's Advanced Air Vehicles Program.

\section{Definitions \& Abbreviations}

\begin{tabular}{|l|l|}
\hline$B H$ & Background humidity \\
\hline$C E$ & Collision efficiency \\
\hline$d_{v 0 . X X}$ & XX percentile cumulative volume diameter \\
\hline$H S I$ & High Speed Imaging probe \\
\hline$I K P 2$ & Isokinetic probe, second generation \\
\hline$L W C$ & Liquid water content \\
\hline
\end{tabular}




\begin{tabular}{|c|c|}
\hline$L W C_{m, 0.5}$ & $\begin{array}{l}\text { Liquid water content, measured using multi- } \\
\text { element probe's } 0.5-\mathrm{mm} \text { diameter wire }\end{array}$ \\
\hline$L W C_{m, 2.1}$ & $\begin{array}{l}\text { Liquid water content, measured using multi- } \\
\text { element probe's } 2.1-\mathrm{mm} \text { diameter wire }\end{array}$ \\
\hline$M M R$ & Mass mixing ratio \\
\hline$\triangle M M R$ & $\begin{array}{l}\text { Mass mixing ratio, delta, cloud-on minus cloud-off } \\
\text { values, }=M M R_{e, o n}-M M R_{e, \text { off }}\end{array}$ \\
\hline$M V D$ & Median volumetric diameter of cloud \\
\hline$M W$ & Multi-wire \\
\hline $\boldsymbol{P}$ & Pressure \\
\hline PDI & Phase Doppler Interferometer probe \\
\hline PSD & Particle size distribution \\
\hline PSL & Propulsion Systems Laboratory \\
\hline RFP & Rearward facing probe \\
\hline $\boldsymbol{R H}$ & Relative humidity (\%) \\
\hline$T$ & Temperature, air \\
\hline $\boldsymbol{T A T}$ & Total Air Temperature (probe or instrument) \\
\hline$T C$ & Thermocouple \\
\hline$\Delta T_{0}$ & $\begin{array}{l}\text { Temperature, delta, cloud-on minus cloud-off } \\
\text { values, }=T_{0, o n}-T_{0, o f f}\end{array}$ \\
\hline$T P L$ & Total temperature in the plenum \\
\hline$T_{w b}$ & Wet-bulb temperature \\
\hline$T W C$ & Total water content \\
\hline $\boldsymbol{t}$ & Leading edge ice thickness \\
\hline$U_{e}$ & Velocity - bulk, test section \\
\hline$W E$ & Water-catch efficiency \\
\hline$\eta_{M R}$ & Melt ratio (dimensionless) \\
\hline
\end{tabular}

\section{Subscripts}

\begin{tabular}{|l|l|}
\hline $\boldsymbol{O}$ & Total or plenum conditions \\
\hline $\boldsymbol{e}$ & Exit or test section conditions \\
\hline $\boldsymbol{i}$ & Inlet condition (at spray bars) \\
\hline $\boldsymbol{m}$ & Measured value \\
\hline off & Cloud-off \\
\hline on & Cloud-on \\
\hline $\boldsymbol{s}$ & Static condition \\
\hline $\boldsymbol{T}$ & Target value \\
\hline
\end{tabular}




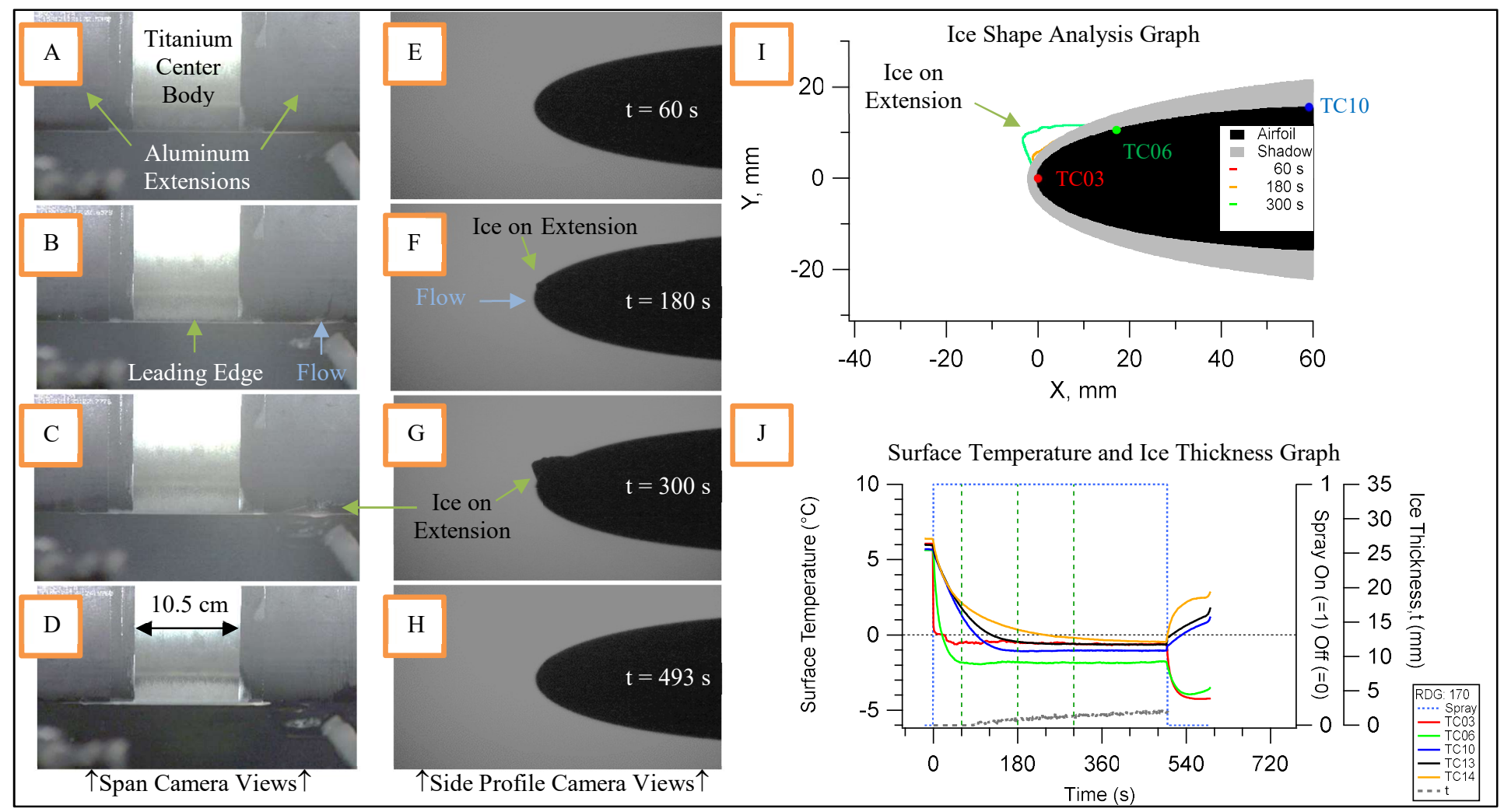

Figure 10. Ice Accretion Images (Panels A-H) and Profile Analysis (Panel I) for Case (a) - Escort 170 (RHo,i=20\%, $\left.\eta_{M R, e}=0.14\right)$. Panel J shows the time histories of surface temperature (colored lines) and leading edge ice thickness (gray hatched line). The green vertical lines in Panel J correspond to the times when the images on the left were taken.

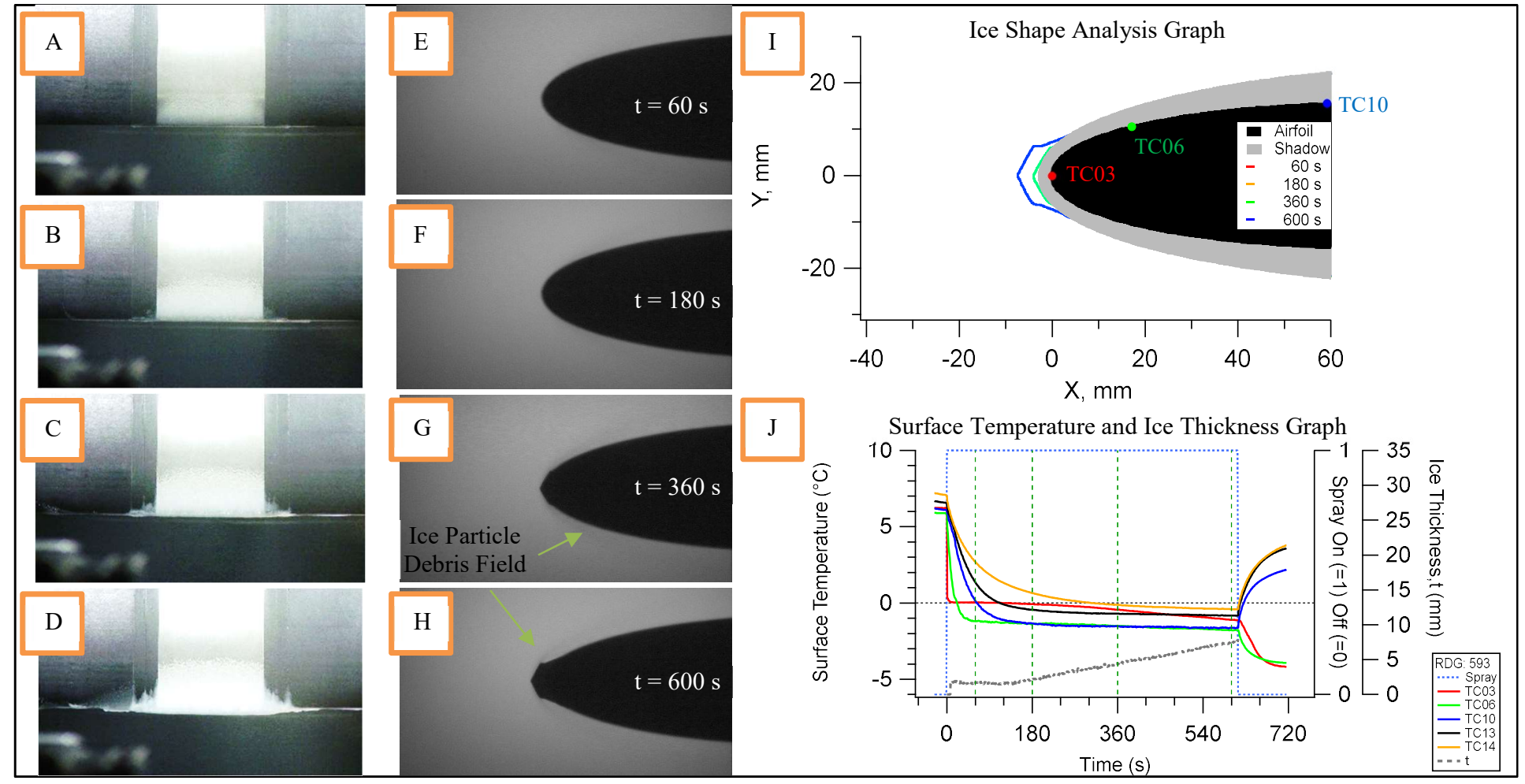

Figure 11. Ice Accretion Images (Panels A-H) and Profile Analysis (Panel I) for Case (b) - Escort 593 (RH $\left.0, i=25 \%, \eta_{M R, e}=0.21\right)$. Panel J shows the time histories of surface temperature (colored lines) and leading edge ice thickness (gray hatched line). The green vertical lines in Panel J correspond to the times when the images on the left were taken.

Page 10 of 11 


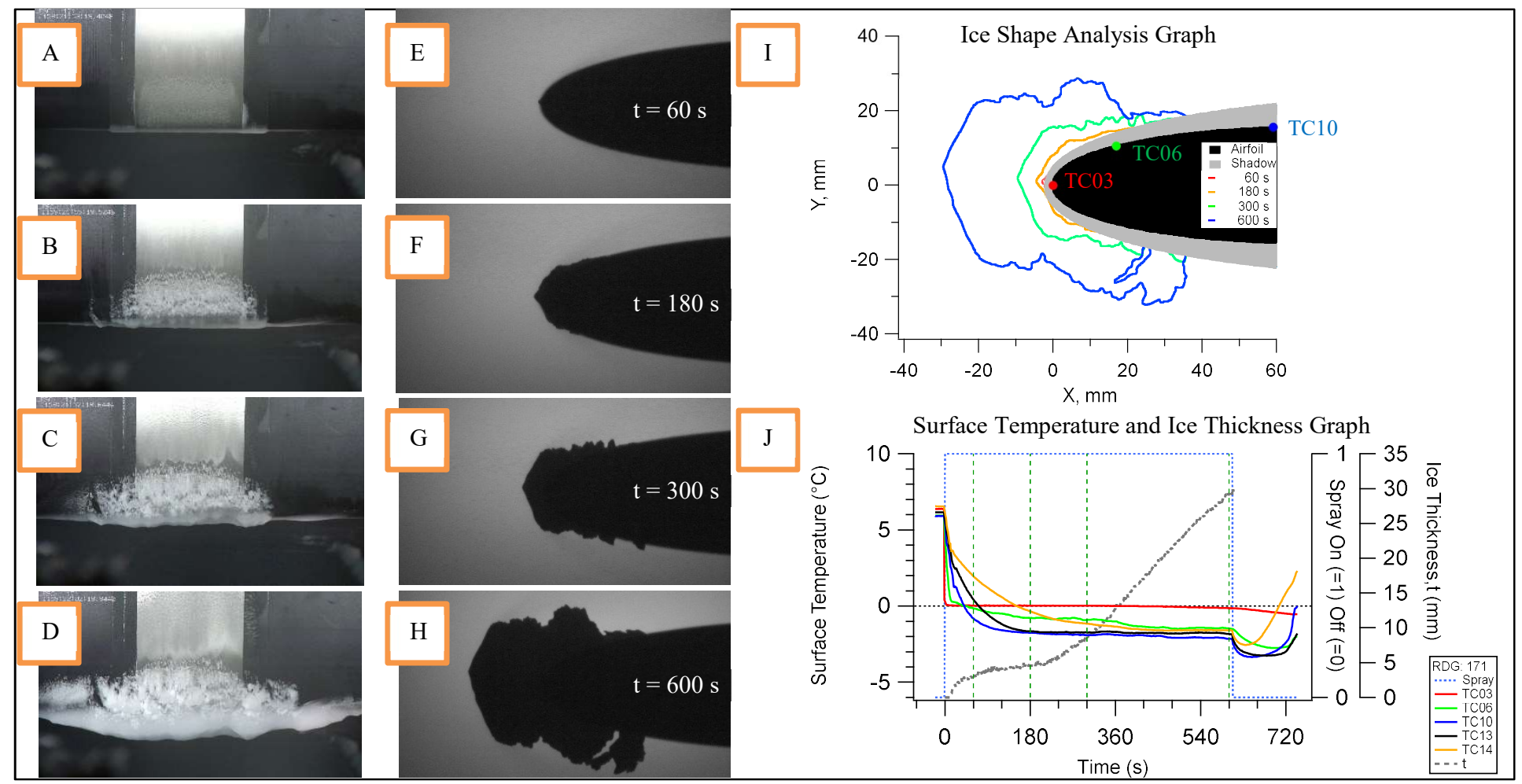

Figure 12. Ice Accretion Images (Panels A-H) and Profile Analysis (Panel I) for Case (c) - Escort 171 (RH0,i = 30\%, $\left.\eta_{\text {MR,e }}=0.28\right)$. Panel J shows the time histories of surface temperature (colored lines) and leading edge ice thickness (gray hatched line). The green vertical lines in Panel J correspond to the times when the images on the left were taken.

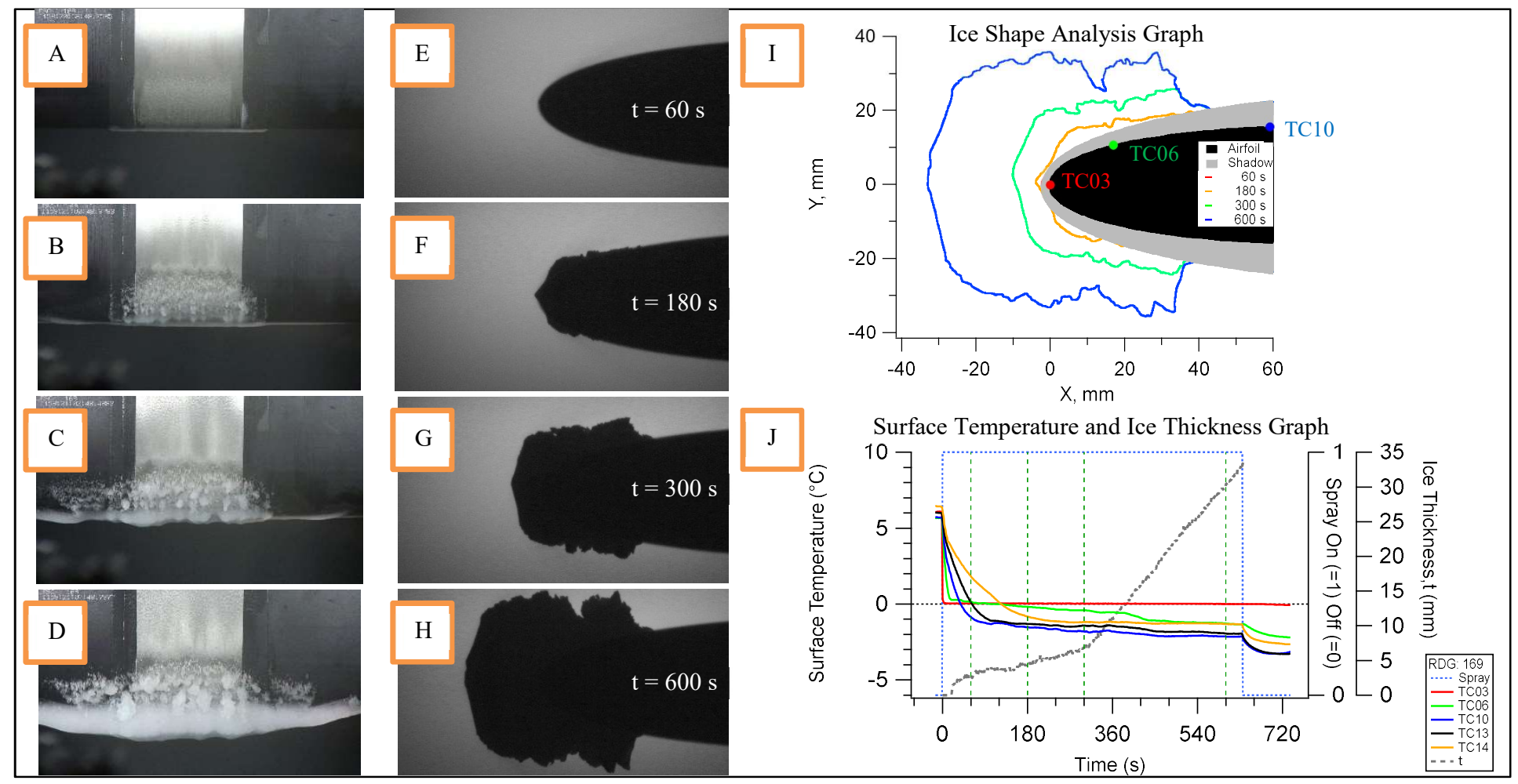

Figure 13. Ice Accretion Images (Panels A-H) and Profile Analysis (Panel I) for Case (d) - Escort 169 (RHo,i $=35 \%, \eta_{\text {MR,e }}=0.51$ ). Panel J shows the time histories of surface temperature (colored lines) and leading edge ice thickness (gray hatched line). The green vertical lines in Panel J correspond to the times when the images on the left were taken.

Page 11 of 11 